Tsavo, including plants eaten by rhinoceros, and the relationship between the rhinoceros and other vertebrates; sub-sections on parasites and diseases, aggression and intraspecific intolerance, and biological characters of the population of a selected area are also included. The second section deals in part with diurnal activity patterns, group structure, reactions to other vertebrates, ritualised and non-ritualised behaviour patterns, mating behaviour, and a description of the bond between mother and calf, supported with meticulous descriptions and extensive documentation of certain aspects of behaviour. Descriptions in general are excellent, though sometimes anthropomorphic e.g. the interpretation of the black rhinoceros's reactions to man in a car. A tendency to generalisations based on little or no quantitative data is perhaps inevitable in a field study of this kind. The authors state categorically that the black rhinoceros does not live in territories, is largely nomadic within the study area, and that the population of Tsavo East is approximately rooo individuals, but none of these statements is supported with precise quantitative data. Nevertheless, the text is packed with interesting and useful observations.

The critical question, whether the black rhinoceros will survive in the changing environment, is still a subject of debate. In the summary the authors suggest that it may be 'the task of man as a conservationist actively to maintain a certain natural equilibrium within the wildlife sanctuaries'.

JOHN GODDARD

\title{
The Problems of Birds as Pests, edited by R.K. Murton and E.N. Wright. Academic Press, 70s.
}

A modern dilemma is the conflict between birds as pests and birds as pets. Some birds take our food, foul our buildings, and even compete for air and land spaces; others have money galore lavished on them, foods provided, buildings built, and air and land spaces reserved for them. On occasions even the same species may be involved in this apparently paradoxical situation; the house sparrow is regarded by some as a pert little bundle of interest and by others as a nuisance and spreader of disease; the feral pigeon, fed and loved by many city dwellers, is often hated by their neighbours; the bullfinch, welcomed to the garden by some, is greeted with dismay by others.

Where there is a conflict with man's material interests it does seem obvious that control, though not necessarily destruction, of some species in some areas at certain times of year is essential. The Institute of Biology's symposium on 'The Problems of Birds as Pests' highlighted, in the papers and discussions collected in this book, the vital need to know as much about the biology of the bird as possible and the effectiveness of the control methods employed. A policy of control should not be based, as some appear to be, on political motives alone, nor should necessary controls be blocked by emotional dogmatism, and we should be prepared to learn by our mistakes. It becomes more apparent that, with some species at least, destruction of large numbers does not effectively reduce the population. In Africa it was estimated that 100 million quelea were destroyed annually, and still crop damage went on with no obvious decrease in the birds' numbers. In Britain shooting of woodpigeons and rooks has not produced a decline in the overall populations. A twentieth-century problem is the use of air space by man and birds and the inevitable dangers of collision, with loss of life and heavy repair 
expenses. The importance of this growing problem was emphasised by the inclusion of six papers and much objective discussion.

The problems are likely to stay with us for a long time, and the Institute of Biology is to be congratulated on bringing together such useful and thought-provoking papers and participants.

\section{P. J. OLNEY}

\section{British and European Birds in Colour, by Bertel Bruun and Arthur Singer. Hamlyn, 70s.}

In this handsome volume Arthur Singer's illustrations of more than five hundred species, excellent in accuracy as aids to identification, appeal to the eye as being lively and attractive. They are well produced even though one or two of the smaller paintings seem to have suffered a little in the process of colour-printing, well arranged and convenient to consult. The textual notes by Bertel Bruun, a Danish ornithologist, are sound and compendious, and his brief introductions to each family are helpful descriptions of habits and habitats. Particularly interesting and helpful to an English reader is the account of the American sandpipers and other waders which are increasingly identified as visitors to our shores and are finely portrayed on pages 124 and $13 \mathrm{I}$.

The introduction (with a vegetational map) stigmatises the boundaries of Europe as being, from a zoogeographical angle, both 'artificial and dissatisfactory', with their eastern limits ill-defined. It is to be inferred from Bruce Campbell's foreword that the authors have resolved this undeniable difficulty by including all birds seen in the European part of the USSR though not recorded elsewhere in Europe. Whether this is more satisfactory than to take a line of longitude, it is hard to say. No doubt it is very difficult to combine brevity with precision in all respects, and the following remarks are not to be taken as expressing 'dissatisfaction' at the general way in which the condensed notes on species are framed. But even after study of the 148 useful distribution maps and close attention to qualifying broad indications of habitat, those who do not already know their European birds and where to look for them may be puzzled at the use of the word 'common' in relation to many species, for example, the red-necked grebe, the rough-legged and honey buzzards, marsh and Montagu's harriers, hobby ('quite common'), collared and red-breasted flycatchers (in open country), corncrake ('locally common in fields') and so on; in dealing with the passerines an effort is made to apply this vague term less loosely.

The distribution maps at the end are preceded by a list of almost eighty 'accidentals' for which there are fewer than five records in the present century. Of these nearly half have been recorded in Great Britain.

HURCOMB

\section{The Kingfisher, by Rosemary Eastman. Collins, 30s.}

The book of the film, The Private Life of the Kingfisher, by the author and her husband, which achieved an outstanding success, recalls Sielmann's film on woodpeckers and his subsequent book telling how it was made. This details the life cycle of the birds which were studied for the film, and it would be surprising if it did not add to our knowledge of their biology. Inevitably they were subjected to a good deal of disturbance including arrangements for filming them feeding their young in the nest- 